University of California, Hastings College of the Law UC Hastings Scholarship Repository

Faculty Scholarship

1975

\title{
Coupling, Parenting and the Presence of Others Intimate Relationships in Communal Households
}

D. Kelly Weisberg

UC Hastings College of the Law, weisberg@uchastings.edu

Rosabeth Moss Kanter

Dennis Jaffe

Follow this and additional works at: http://repository.uchastings.edu/faculty_scholarship

\section{Recommended Citation}

D. Kelly Weisberg, Rosabeth Moss Kanter, and Dennis Jaffe, Coupling, Parenting and the Presence of Others Intimate Relationships in Communal Households, 24 Family Coordinator 433 (1975).

Available at: http://repository.uchastings.edu/faculty_scholarship/1199 


\title{
Coupling, Parenting, and the Presence of Others: Intimate Relationships in Communal Households*
}

\author{
Rosabeth Moss Kanter, Dennis Jaffe, and D. Kelly Weisberg**
}

\begin{abstract}
This paper considers the nature of couple and parent-child relationships when family space is public rather than private, and others are present as audiences, claimants on the intimate territory, and sources of alternative ties. Research on 35 urban communal households found an initial shift in the locus of social control when intimate relationships are conducted in the presence of "others." Couples experience pressures toward individuation, autonomy, and egalitarianism, and a loss of sovereignty. Parents experience diminishing rulemaking and enforcing abilities and increased self-consciousness along with child care help. Children aged five to eleven are the recipients of increased rule making by a large circle of adults.
\end{abstract}

What happens to the most intimate human ties when the territory of the relationship is shared with others? What happens to couple and parent-child relationships in the presence of other adults who have equal claims on the household? What is the structure of the environment for couples, parents, and children when family space is public rather than private, when others are present as audiences, claimants on the intimate

\footnotetext{
*Portions of this paper were presented as "The Communal Alternative for Couples and Parents," at the annual meeting of the American Psychological Association, New Orleans, September 1974; and as "Parenting and the Presence of Others," at the annual meeting of The Society for the Study of Social Problems, Montreal, August 1974. Data were collected under a grant from the National Institute of Mental Health, MH-23030. The additional assistance of Marilyn Halter, Patricia O'Brien, Carol May, Paula Rayman, and New Communities Project, is gratefully acknowledged. Any names of groups and individuals mentioned in this paper are pseudonyms.

**Rosabeth Moss Kanter, Ph.D., is Associate Professor, Department of Sociology, Brandeis University, Waltham, MA 02154. Dennis Jaffe resides at 11967 Walnut Lane, Los Angeles, CA 90025, and D. Kelly Weisberg is a Ph.D. candidate in Sociology, Brandeis University, Waltham, MA 02154.
}

territory, and sources of alternative ties? We have studied urban communal households-domestic collectives-in an attempt to answer these questions about the nature of important relationships in the presence of others. Rather than focusing on the group as the unit of interest, then, we are focusing on how specific relationships are affected and changed by sharing a household with other adults. Although the setting for this research is a particular kind of family. experiment in the 1970's, many of the results can be generalized to any situation in which outsiders are present in the intimate space of a relationship, whether the "others" are relatives, boarders, close friends, or professionals such as family therapists. The study of relationships "in the presence of others" also highlights, by contrast, a variety of taken-for-granted family dynamics.

The major effects can be summarized as an initial shift in the locus of social control. When relationships are conducted in the presence of "others," couples and parents experience a loss of control, both over their territory and over their partner. The "others" change the relationship by their presence as an audience, direct 
intervention, their availability as potential coalition partners, and their claims over the intimate space. Couples experience pressures toward individuation, autonomy, and egalitarianism, as well as a loss of sovereignty. Parents experience diminishing abilities to make and enforce rules and increased self-consciousness about child rearing, as well as important help in many of the tasks of parenting. Children, of ages five to eleven, who gain additional adult relationships, are also the recipients of increased rule making by other adults. And, paradoxically, while both couples and parents report a loss of control, they still tend to have more power in the household than other adults uninvolved in relationships, so that while they report their lack of control, other household members report the "unfair" control of people in couple or parent-child relationships. These effects are strongest in the early stages of communal involvements; over time satisfactory accommodations tend to be made.

Our research has involved field work, interviews, and instrumented data collection with members of 35 urban and suburban communal households in the Boston and New Haven areas since March 1972, fifteen of which include children under twelve. Single people outnumbered both couples and parent-child units, with few households containing more than one couple or one parent. A majority of the parents were single parents, thus making the analysis of the parent-child relationship in communal houses as a "dyad with others present" even more meaningful. The culture of the households was solidly avant-garde middle class rather than hippie or student. They were generally located in a large old house in middle class areas; relatively few were in hip-bohemianstudent areas of the city. Mean household size was 9.6. Interviewed in depth were couples, parents, and children who had lived in a private household at least six months before beginning to live communally; most of the couples studied were married.

\section{Theoretical Background}

Georg Simmel's work on the significance of numbers for social life and theories of coalition formation that derived from it provides one framework for understanding the significance of the "presence of others" (Simmel, 1950; Caplow, 1968). Simmel asserted that a dyadic relationship is completely different in form from a relationship between three or more people and, in fact, that the change from two to three-or-more parties is one of the most significant numerical leaps. The two-person relationship is a union, two complementary and unique parts coming together; it may come to depend upon a division of properties such that persons experience their own incompleteness without the contribution of the other. Each one constitutes the relationship; it would not exist if either one left. The person least involved may have the most power, according to the "theory of least interest" derived from this analysis, because if either person leaves, the relationship by definition ends. Each person is a majority, so the power pattern is normally one of dominance-submission. Equality is hard to achieve if there are two opposing interests clashing.

With the introduction of a third person, the relationship may drastically alter. The third party provides an audience for the initial dyad and merely by watching may alter the relationship in a number of ways: by serving as a representative of "society" or interests beyond the dyad (a reminder of social norms), and thereby increasing the self-consciousness of the pair as they interact and increasing the pressure for imagemaintenance; by serving as a witness and potential swing vote should the dyad engage in dispute; and by becoming privy to "family secrets," thereby reducing the space in which one important solidifier of relationships can be maintained. As coalition theory suggests, a third party also makes possible coalitions and power blocs other than the original couple, thus dramatically altering the power structure, since it is now possible for any two to form 
a coalition against any third person or one person to set another two against one another. Power cannot as easily be unilaterally exercised by one dyad member over another because of the threat of third party intervention or the forming of a superior coalition with the victim.

The nature of group dynamics differs in additional ways in three-person versus two-person groups. Relations of three or more, Simmel theorized, are based on what members have in common rather than their unique properties emphasizing a union of commonality instead of the union of opposites of the dyad and de-emphasizing polarization. Finally, Simmel proposed that relations of three or more have a "superindividual" reality such that any one of the members can leave but the relationship, the unit, the group, will still exist. Unlike the situation of the dyad, members can be replaced without totally changing the unit's character. The three-person group is thus theoretically immortal, and the "principle of least interest" that gives power to the member threatening withdrawal is no longer automatically operative.

If the larger group is a potential threat to the freedom, sovereignty, power configuration, and division of properties of the dyad as an exclusive and excluding relationship, the two-person intimate alliance may also be a potential threat to the solidarity of the larger group. Several analysis suggest that, particularly when the need or desire for collective commitment to "superindividual" entities is high, exclusive relationships such as couples and parent-child bonds may threaten the group because they represent competition for members' emotional energy and loyalty; because they may be self-sufficient in themselves, not needing the group and leaving it behind, withdrawing their resources and shutting others out; and because they may represent a natural power bloc within the group with the advantage in coalition formation of easier access to and knowledge of one another (Kanter, 1972a, 86-7; Slater, 1963; Coser, 1974). When things are difficult in a group, people in committed subgroup relationships may also have the advantage over nonrelated people because they do not "need" the total group to the same extent; such inequalities may threaten group cohesion and satisfactory resolution of the dispute. In a variety of past and present communes, for example, groups developed a number of practices to reduce the importance of biological family ties and increase the number of functions served by the whole group rather than the small unit (Kanter, 1972, 1973). Philip Slater (1963) has described the mechanisms by which society in general intrudes on couples and families, reasserting control over them and pulling them back into the social fabric when they threaten withdrawal and secret behavior free of social constraints.

Thus, intervention into the relationship of a couple or parent-and-child may not only be made possible by the presence of others but may also be actively sought by the others in order to reduce the threat of dyadic withdrawal and maintain the cohesiveness of the larger unit all comprise. Several propositions follow. For example, helping one dyad member with a responsibility involving the other is also a way of intervening in the relationship and indicating the potential replaceability of a partner, thus undercutting both the exclusiveness and the self-sufficiency of the dyad. In collective households, then, the amount of helping people do with each other's needs and obligations, from babysitting to providing company while the partner is out, serves both a manifest function of reducing burdens and a latent function of helping prevent dyadic withdrawal. Further, we can propose that when others intervene in a dyadic relationship, they are likely to try to maximize keeping both members actively available to the group-supporting the weaker member against the stronger so that the stronger will not "destroy" the weaker, and supporting the one who is being pulled into withdrawing against the one who is pulling. Finally, when collective commitment is important and the dyad is not necessary as a fundamental building block 
of the collective, we can propose that when third parties serve as audiences representing social norms, the norms of which they remind the pair are likely to be norms against dyad unity and fusion.

This theoretical overview makes apparent a fundamental asymmetry between how dyad members and third parties would view their joint relationship in a three-or-more person group. While pair members may experience the loss of control over their relationship and joint space and the control of third parties, the "others" may themselves feel out of control of the situation in the presence of the "natural coalitions." Paradoxically, while dyad members may feel they do not have enough power in the presence of others, the others may see them as too powerful. While dyad members may feel they give up control, the others may instead feel they take control. This situation engenders a number of tensions in the group and an atmosphere in which dyad members are continually aware of working on contradictions and balancing pulls.

The analysis thus far is relevant to any relationship of three-or-more roughly equal participants containing committed dyads. But we suggest that these phenomena are exaggerated in communal households and therefore more visible. First, urban communal households intentionally develop a public character that makes others potentially present for generally all family events but sleeping, sexual intercourse, and bathroom use. Group members also have access to and claims on all household territory except a member's single private room, and sometimes even that place if the door is not closed or the resident not present (Kanter, 1974).

Secondly, communal households generally stress negotiated as opposed to institutionalized norms. Since there are few precedents for organizing collective households and often explicit values favoring shared power, members must come together in a period of initial chaos, high expectations, and sometimes conflict and confusion, to create a household organization. House meetings at weekly or biweekly intervals are often the first process established. The emphasis on negotiation-which we suggest will be characteristic of most families in the future-stems from the ideology of alternative families as well as the structural consequences of joint residence by many equal, unrelated adults. House meetings and other public negotiations aid shared power and meeting on common ground, even if there are age or resource differences. The existence of egalitarian norms means that when others intervene in a dyad they are as likely to support the weaker as the stronger member.

Finally, the household's division of labor is also the result of an explicit small group negotiation process. It is likely to be determined on the basis of fair sharing of the load rather than skill or ascribed characteristics, and it is likely to involve every member, often including children, as an individual rather than as a member of a unit. (Job sharing, indeed, is another way in which collective commitment can be enhanced. See Kanter, 1972.) This and other structural and other ideological characteristics of communal household increase and channel the effects of the "presence of others" on couples and parents.

\section{Couples: Diminished Sovereignty}

When a couple moves from their own place into a public household, their initial experience 'is a loss of power and sovereignty, combined with an opening up of their relationship to others. Since the couple members are not the sole proprietors of the house, they have less autonomy, privacy, power and freedom to set rules than if they lived alone. This can be stressful, but some people also find it a positive experience, especially if it is in line with one's ideology, as it was for this woman:

\footnotetext{
I learned a lot about sharing. I had lived five years in a couple and had really got into some privatistic things. Control things like always knowing what's in the refrigerator; little things that psychologically make a lot of difference. Taking control of the house and knowing what
} 
had to be done, and planning around that. At first it was difficult for me to lose that control, although it was also liberating. I sometimes didn't have input into what we ate, which brought back bad memories of my parents' house. Or we would get a lot of magazines, which we would save. But in the commune they would get lost, and I had to change my feelings about those pieces of property.

As a subunit of the house, one's couple is not identical with the whole, but is subject to observation, as well as checks and balances by other people.

Having an audience can be disconcerting at first, as this man felt: I wasn't convinced that I wanted to have other people observing my idiosyncracies and challenging me, wondering aloud why $I$ did $x$ or $y$. Suddenly all of my routines were subject to scrutiny, things that the other member of the couple would just let by. Like my fixing everything in the house, which would now become issues, because suddenly it wasn't my house. I didn't have to be responsible for everything, because others wanted to know how to take care of the house too. So in the process we started to question these roles.

The audience alters the way one deals with a mate as well. One person reported that in his nuclear household he could go on a unilateral strike, as by refusing to talk to the other in the face of repeated demands to take out the garbage. In a communal household, the presence of an audience witnessing this "childish" behavior and able to step in the breach, potentially isolating the agressor, makes this strategy less effective.

In a communal household, couple members cannot control all inputs and outputs for themselves and each otherwhether material or emotional. This makes the couple boundary more permeable and intimacy more diffused. The limited exchange of interpersonal goods and services within the couple is replaced by a marketplace, in which different possible relationships and experiences are available from a variety of others. Some of the couples were at a stage where they felt their relationships were becoming stale, boring, routine and depressing. New people represented an injection of energy, and forced them to re-evaluate their relationship, as this man found:
Initially I had two distinct feelings. First that I was losing my family. I was afraid of that. I liked the family set-up, the closeness to the children. I felt the nuclear feeling, closeness, was going to be gone forever, and that has turned out to be true. The other feeling was one of camaraderie. Here were people I loved setting out on a frightening, glamorous, together thing. We had a chance of really experiencing close friendship we couldn't get in other ways. So there was fear and optimism at the start.

Almost every couple interviewed remarked that living collectively resulted in their learning that if and when their mate cannot meet a particular need, there are others who can. They find that many of the conflicts they had as a nuclear couple are less intense, because the other no longer represnts a unique and irreplaceable resource. This both takes pressure off their relationship, and decreases its intensity-a potential gain and a potential cost.

The loss of sovereignty and opening up to new relationships that couples experience creates an element of risk which is not shared by single commune members. Since the commune upsets the balance of the relationship, opening it up to new inputs and sources of control, and diffusing the focus of couple members on each other for gratification, one is testing the relationship when one enters a commune. There is always the possibility that the relationship will be totally replaced, or cease to be useful within a communal context. The commune removes barriers to temptation and change, and a relationship that cannot stand comparison will probably not stand up to communal living. This factor probably accounts for the high number of couples who split up within the first few months of communal living (nearly 50\%) and the very low number of splits that occur later (Jaffe and Kanter, 1975). Couple members who split up after moving into a commune usually report that the commune hastened or catalyzed a seemingly inevitable process, or gave them the support to leave the relationship or invest in new ones. An empty shell couple has little reason to remain together within a commune. 
Interventions and Coalitions:

Heightened Conflict Expression

Other household members can actively intervene or form supportive coalitions with one member of the couple; thus there is opportunity and pressure for the couple member to open up conflicts. Said one woman:

\begin{abstract}
When there's other people around, you can express that conflict, your difficulty, whereas when there's just the two of you you have these old patterns, like you get angry and it doesn't affect anyone else, you're just angry for a couple of days, and the other person learns to ignore it. You don't talk about it or try to realize what's making you angry. When you're living with other people they are affected by it so you have to be more critical about what's happening to you emotionally, and the effects of your behavior on other people.
\end{abstract}

In many groups, couple issues that cause strain for others are resolved either by house members talking to the couple privately, or being sought out as mediators by the couple. Couples who feel that their relationship is only their business are usually those who withdraw from the house in other ways, and soon move out of communal settings.

Conflict expression and seeking support outside the couple is facilitated by living with others of one's own sex, since same-sex coalitions are more or less "natural" alliances (Caplow, 1968). Almost all of the people we interviewed had been affected by the women's movement, especially its aim to allow women to gain a sense of themselves by breaking down a woman's identification with her man. Most of the women in communes, and many of the men, have been in women's or men's consciousness raising groups, and through such groups they learn to identify and seek support from people of their own sex, which breaks down dependency on one's mate for such support. Many of the communes had women's groups, meeting intermittently or regularly. One commune separated its house meetings into men's and women's groups. The women began to talk about how the married and single women were competitive and jealous, and how this inhibited their closeness because they were still into societal roles of either protecting their man or feeling bad because they didn't have men. The men, meanwhile, had to deal with the ways in which they used women to deal with feelings, to bring up issues around feelings and generally to keep the social life of the house together. They began to take initiative around these areas, discussed problems in their couples, and began to do things together.

\section{Pressure for Individuation and Autonomy}

Since there are usually single people, and since almost everything from decision making to task allocation is expressed in terms of individuals, one of the major effects of a communal environment on a couple seems to be that it shifts their definition of themselves from being "part of a couple" to "individual member of the commune." Couple members thus lose control over their partner at the same time that they lose their special couple sovereignty over their household.

This changes both the way each member of the couple sees himself/herself and the way he/she behaves. Couple members reported that previous to living communally they felt treated as an inseparable twosome: they were viewed as part of a couple, rarely went places or maintained friends alone, the wife expected to identify and gain status not from her own but her husband's achievements, and the two were taken as a single conversational unit, in which the opinion of one was assumed to stand for both. Several couples mentioned the difficulty of keeping single friends, the norm being you have another couple over the dinner and maintain a very structured relationship with them, rather than drop in or maintain individual friendships. One woman mentioned that she felt guilty if she went out, because she would be leaving her husband alone to babysit. Also, many traditional couples have a norm that they cannot disagree or neglect to support the other person in the presence of others, even though they may later disagree violently.

The communal house seems to reverse each of these fusing processes, by 
structurally reinforcing the autonomy and individuality of each member of the couple. Couple members feel freer to come and go, develop relationships, and act without their mate. For example, if one member of a couple is at work, the other who might be in the commune with the children will be relating individually to other commune members. People can go out without feeling that their mate will be all alone, so there is no longer pressure, for example, to go to movies or concerts or parties which one does not care for, just because the mate is going. Of course this process does not go smoothly.

One husband talked about the change in their relationship, which occurred in the year they began to live communally, after many years of very traditional marriage and child rearing:

We began more and more doing things on a
completely individual basis, following our
interests whether or not they included the
other. Like, quite recently the weekly women's
meeting began, and Elaine has had long talks
and strong friendships with people here that
don't involve me. . The biggest change is this
recognition of each of our individual lives out-
side of our relationship. I have recognized that
there is less of my life tied up with her, whereas
before I was married 24 hours a day, my entire
life was in relation to her, whether something
was happening or it wasn't. Now there are
parts of my life that she doesn't enter.

As a couple they have had conflicts over her feeling that he puts his relationship to the community above her-something he admitted and tried to moderate. He felt that they had been at a point where they had little in common, and now that they recognize their separateness, they can also recognize what they share.

Communal households reinforce individuation by making membership and citizenship available only to individuals. Each person joins individually, and usually states individual reasons for wanting to join. When a house member forms a couple with someone outside, it is never automatically expected that the new person will move in; the new person must ask for membership individually, or in one household has the special status of "consort" until he or she becomes a member. There is also pressure for couple members to make decisions and participate in house meetings individually. As people get to know them individually, and under the conflictual lens of house meetings, the facade of couple agreement can no longer be maintained. Many house members talked about how they welcomed times when one member of a couple was away, because that was a way of getting to know the other person separately. Couple members likewise valued time around the house when their mate was absent as a time for forming individual relationships to others. Couple members reported that when they behaved as a traditional couple-sitting together at meals, performing house duties for each other, always agreeing, cutting each other off in conversation, or immediately going to the mate when they come home, expecting them to stop what they are doing-they are apt to be confronted by others, who feel left out or uncomfortable at such closed boundaries.

At the extreme pole of individuation lies the couple that substitutes membership in the community for couple membership. Although only a few couples reported that they joined communes with the intention of making the relationship to the commune primary, simply drifting away from a couple relationship is one possible consequence of individuation. A woman tells of how she moved out of an unfulfilling couple:

\footnotetext{
Al was particularly concerned with privacy when we were having a discussion or argument or anything personal between us. Much more so than I. And he didn't really want to go into the conflicts we were having, but just to sweep them under the rug. Since both of us were pretty involved in community things it became harder to nourish our relationship. We didn't work at it hard enough. Our expectations and our interests diverged. We looked in the community to each follow our separate interests, so we didn't have to share. That was happening so nicely that we were spending less and less time together. Our time together would be with other people around so it wasn't time for us but for community, and didn't help our relationship. It became a substitute for the relationship.
}

Each of them eventually became involved 
with other people who more closely shared their interests. She spent a summer traveling, and then returned and took a separate bedroom. Neither of them felt an immediate need to resolve their relationship, which existed in a state of separateness and ambiguity until a year later, when they formally acknowledged their separation as a permanent fact, and began living with other people.

This is just one extreme example of how communal settings may even support a complete severing of the relationship: one may remain part of a "family" while leaving a couple, continuing the relationship to the group. In many houses each individual has his or her own room, so that in some cases a split does not even necessitate a room change. There were several instances where both members of the former couple remained in the house after severing their relationship, though not without tension.

\section{Pressure for Egalitarian Relationships}

While the pursuit of autonomy and stress on individuation is a force toward equality, there are additional ways in which the structure of the urban communal household promotes male/female equality and a decrease of sex role differentiation among couples. Ideology supports structure: all the communes we studied are explicitly against male dominance (in contrast to some spiritual and rural communes), and are actively trying to equalize sex role related behavior around the house (see Kanter and Halter, 1973). A communal household does not automatically allow the institutionalized slipping into complementary roles and functions - a rigid division of labor based on sex-which can easily occur between two people whose relationship may depend on such division. In many cases neither member of the couple likes housework, and the communal environment decreases the total amoung of work each person must do, so that "oppression" of the female via unwanted housework is not simply replaced by male drudgery. Also, people report that many people working together cleaning the house for a few hours a week is more pleasant than working alone. There is less work for all, so when men are asked to participate the demands are not so onerous. The group negotiation process also makes it difficult to maintain a sex-related division of labor. One man reported:

Sex roles have become less important here.
People all do certain things and the roles are
becoming less and less defined. Some women
like to work around the house, and all the men
help cook, and clean. It wasn't so for us before.
I worked and she took care of the kids. At
times I took over some of what I always
considered to be "her" work. Now I don't see it
as hers any more, we simply help each other. I
never did much cooking, but here I do it
regularly. It is my contribution to the
community rather than me giving her a hand,
which incidentally, I always needed to be
thanked for, because I was doing a favor,
something I didn't have to do.

The presence of a same sex reference group enables many groups to resolve couple role conflicts in favor of greater sharing and equality. Many groups use the word "struggle" in connection with this process of sex role redefinition among couples, and in general among men and women living together. They use group meetings to deal critically with the meaning of equality, to give feedback to others who are not aware of the implications or meaning of their behavior, or are not changing in ways that the house had agreed to. Thus, change of behavior in a communal setting can be monitored constantly. Couples who might have difficulty resolving sex role conflict, or might agree in principle but argue over pathways toward their goals, now participate in a forum which clarifies goals and can judge the degree to which they are met.

\section{Couple Power and Couple Boundaries}

Although couple members experience a loss of control, they may still end up with more power than single people in a communal household. Couples retain some control over their own relationship, and there are several ways in which their existence as a couple (particularly in the majority of houses which are largely 
populated by single people) can gain them disproportionate power.

In some groups, for example, there is a "first family," a couple that takes on some characteristics of a set of parents. They may attain such status because they own the house, or initiated the household, or because they are the oldest members (in age or time lived communally), or simply because they are the only couple. Such "parent trips" in communal households are often a source of conflict and difficulty. Incidents such as the male member of the only married couple handling all the financial affairs, with the others periodically complaining about this but not initiating an alternate plan, demonstrate the tendency for communes to break down into conventional sex role behavior, despite ambivalence about it. Thus, in some houses the existence of a parental couple is a source of comfort, with members differentially seeking them out for advice and support, while in others "parent trip" is an accusation, a protest against the real and imagined authority of a couple. The symbolic role of a couple, especially one with children, is such that members of a couple were routinely the most influential in their communes.

Couples have the advantage of not needing the group for emotional sustenance to the same extent that others may; couple "withdrawal" is thus often a reality as well as a threat. Couples may often experience their communal life as a fluctuation between periods of withdrawal into nearly exclusive focus on their couple relationship, and periods of involvement in community activities such that the couple is nearly absorbed into the household, with each member pursuing his or her own activities. The other members would obviously prefer the latter pole, but due to threat, preference or mutual commitment, couple members often feel they have to withdraw into the couple, forming in a sense a mini-nuclear family within the group.

Couple withdrawal is especially threatening in households where there are single people who do not have the option of withdrawing into a couple for emotional support or relief from the community. According to one woman in a couple:

\begin{abstract}
For us, a couple, the commune was wonderful, a dream. It was shitty for single people. There were only two of them. The other couple were having problems, so they became sort of clingy when they were together. Sharon had her insecurities and not being in a couple heightened that, and there was no way to deal with that. Single people don't enjoy it. You have an issue that you talk about around the table that's really heavy, and then I could go back to the bedroom and talk with Ron, so I have three hours of support to work it through. Sharon would have no idea even what the issues are and no support. Sometimes she hears about the issue, but mostly she doesn't know. whether because of privacy or simply time. So I have double support. The upshot is that Sharon will live in a woman's house next year.
\end{abstract}

In several houses which contained two couples and a fifth single person, that person was always peripheral to the community, feeling lonely and usually developing an outside relationship and having a very low commitment to the commune.

Couples in communal settings also derive power from the ways in which they maintain their boundaries and thus exclude others. The couples we studied set limits to the diffusion of intimacy. While there are many needs that others can satisfy, there are many ways in which the intimacy of the community are expressed, multiple sexual relationships are hard to maintain, and are a regular part of very few of the communes we studied. Our findings contradict the media view of sexual libertarianism as a central feature, at least of urban communes. Nearly all of our communes show a preference for couple members not developing sexual relationships with their housemates. After a while most groups develop an "incest taboo," which seems to be a source of stability, and sexual experimentation for couples occurs largely outside the commune. Similarly, single people who attempt multiple relationships within a commune seem to drift into couple relationships. At present it seems that the family-like intimacy that is the goal of 
communes does not include shared sexual relationships, probably because the jealousy and comparisons which occur tend to disrupt the weaker of the relationships even more dramatically than other forms of sharing, leading to one of the participants leaving the commune.

The couple may also maintain other limits: emotional and informational as well as sexual shared "secrets" and private knowledge, including the knowledge that stems from private discussions behind closed doors, are important mechanisms of exclusiveness and solidarity. Couple members generally have several sources of intentional and unintentional private knowledge such as how the other feels about an issue before it is openly discussed; they may also have a longer shared history. Their knowledge of each other-sexual, psychological, biographical -is generally greater than that of other members. And couples may also deliberately generate their own "secrets."

While the other members are privy to much of the couple's personal and emotional life, the traditional norm against a couple discussing their relationship with outsiders, or when one member does, for the outsider to feign ignorance, still looms large in many communal houses. In only a few households, primarily those with a radical feminist orientation and those having several couples, do couple members make a commitment to be open with the commune about conflicts and issues within their relationship. Maintaining the confidentiality of the couple seems to be a homeostatic mechanism, which is usually broken only in times of great stress and conflict. For example, in one commune it was obvious that one of the couples had a very traditional relationship in which the women was passive, dependent, and powerless, but this was never mentioned openly. Then, another woman in the commune got into a conflict with the male member of that couple around his disrespect for her own autonomy and dismissal of her as a person, which in turn exposed both weakness and strain in his couple relationship, and led to a process which eventually ended in the woman receiving support from the other members of the house to ask her mate to leave.

But usually the process of becoming aware of a couple's relationship is more circuitous, and extends the stress that the couple is under to other members of the house. Either the couple gives out signs of stress, depression, or anger, such as by making biting comments or not doing their housework, or else one member of the couple may seek out another house member. (Interestingly, both men and women in couples tend to confide in other women, perpetuating another sex role related dynamic.) The other person is then in the difficult situation of knowing something, yet facing a norm against communicating either their knowledge or their own feelings of helplessness or discomfort. This may cause strain for the whole community.

Finally, when it will help a couple gain its private ends, couples may approach the rest of the group as a power "bloc." The couple has several weapons: to claim superior "need" to the extent that more people or more complex situations are involved; or to threaten withdrawal (emotional or physical) if the group is not responsive to couple demands. Such levers may enable the couple to gain privileges or concession, as when couples routinely claim the best rooms or have more influence over guest policy. Couples have the knowledge that if they maintain some of their own boundaries, they can always simply reform their isolated unit, excluding the others, when things go poorly.

Much of the behavior of others toward couples may thus be seen as a response to couple power. Although the households we studied, unlike traditional or religious communes (Kanter, 1972, 1973), did not develop formal mechanisms to regulate couples and place them under the control of the group, they do exert group pressure on couples not to withdraw and to form relationships (coalitions) with others. This pressure may occur even in relatively loose households around casual couples. One member reported:

There were subtle hostilities from almost everyone being directed at their partial withdrawal from the rest of us into their own world. It 
came out in criticisms of their relationship by various people. . . It's true that if you start to get into a heavier-than-usual relationship with anyone, you should have every freedom to let it develop. Living in a commune, however, carries with it a responsibility to maintain a certain amount of awareness of where everyone else is at and how what you are doing is affecting the total group.

\section{The Delicacy of Couple Existence}

Many couples thus find that the issue of their withdrawal versus the commitment and participation in community activities is their first confrontation with the meaning of communal life to their relationship. Experiencing the withdrawal of the privacy and psychic space they may have been accustomed to, many couples report an initial defensive overreaction. Their first encounter with the super-individual entity "the commune," which makes claims on them, makes them feel they have given too much up already, while their housemates paradoxically feel they have not yet given enough. Some couples react to these demands by trying to reestablish autonomy over a smaller space. They may fix up and spend time in their private living space as though it were a separate complete home-in several cases with small kitchen units and private phone so that the couple could reduce its need to leave its own quarters. Couples may create informal barriers to entering their rooms except at certain times or under certain conditions, or do their household chores together. But if they ideologically desire to deprivatize their relationship, and not enter the commune as a unit called a "couple," they will also face additional pressure to live up to their beliefs.

\section{Parents: The Dilemmas of Sharing Responsibility}

Parent-child relationships are affected by the structure of a communal household in many of the same ways male-female couples are, by the parents' diminished sovereignty over the household, the presence of an audience and potential coalition partners, and pressures for individuation and autonomy. For parent- child units as well as couples, the communal household replaced the nuclear family's limited exchange of goods and services with a market place. Since the family's exchange is usually one-sided, with many more goods and services flowing from the parent to the child than in the other direction, many parents, indeed, come to communal households seeking the market place: a sharing of child care responsibilities, a provision of inputs from other adults, the presence of others to take over when the parent is depleted-that is, a change from obligatory exchange, in which the parent must give to the child, to a free market, in which the parent can choose when and how to give the child because he or she is one of a number of resource-holders. One reported:

\begin{abstract}
The house took the pressure off. When I was the only Mommy I lost my temper a lot more. There was no relief. Living alone with them I was terrified that I'd get sick. There was absolutely no one else. Here if I have some problem there is always someone to take care of them. So relating to the children is a lot freer. I do it because I want to, not because I have to.
\end{abstract}

Generally others helped through casual babysitting, performing household tasks in the communal division of labor, and distracting children's attention. While the diffusion of dependence helped parents with their burdens, it also provided children with numerous and easily available alternative relationships within the home, as a mother indicated:

\begin{abstract}
It's a very positive thing. Children should be raised this way; they shouldn't be isolated. Adults aren't isolated, even in the nuclear family. But the chils is in a prison. . . . Communes are the feeling of neighborhood that there used to be; you had your groups of kids after the day in school. You don't see it in suburbia; you don't see it too much anywhere. But here we have it.
\end{abstract}

Rarely did parents report in interviews that they had as much help as they wanted. One single father, for example, felt that he did " $98 \%$ " of the child care in his household, even though others frequently took care of his four-year-old daughter when he went out. But it is also clear from our interviews that the parents 
themselves often erected barriers to the involvement of others during the initial stages of communal involvement. The diffusion of responsibility and intimacy seems to be threatening for communal parents perhaps even more than for communal couples, who may be consciously or unconsciously looking for ways to disengage. The parents we studied were concerned about the loss of control and loss of intimacy that sharing child care might entail. One woman who had lived alone with her husband and four children before creating a communal household indicated that she found it much harder to let go of parent-related jobs than other domestic chores she had enjoyed performing, even when the jobs were routine and inconvenient, like getting the children's bath at night. A woman in another house seemed to exude ambivalence. She expressed a desire to give up her "fused identity" with her child but indicated pleasure over the strength of the bond that created:

I'm trying to loosen possessive feelings around a kid, giving up some of that. Letting other people parent her, the decision to give up my total investment in her creation, was hard. I I can no longer project myself and invest in making her my ideal. It's risky in a way, to give up some control.

The presence of others complicates parent-child relationships and diminishes parental sovereignty at the same time that it offers relief from exclusive task responsibility.

\section{Audience Effects and "Reflected Identity"}

The presence of others affects parental control in several ways. First, others act as a virtually ever-present audience to parentchild interactions, especially at meals and in play situations. Many communal parents report greater self-consciousness about rule-making and rule-enforcing when others are there to witness them. They indicate a greater concern with demonstrating consistent, reasoned discipline, in part because of awareness that the child may have a champion if the parent mistreats him/her. For some parents, this means that they hold back, try to control their anger, and refrain from disciplining or restricting the child as severely as they might without an audience. Oten the issue of reflected identity arose even among people experimenting with a new culture. One mother reported her feelings that what her son does reflects on her:

Every time Jonathon (three years old) spills milk I feel I have to get in there and wipe it up fast. I consider it my responsibility; it's a test of my ability as a mother to try to teach him not to do it.

Another woman indicated she was sensitive to other adults' opinions of and expectations for her child; at first she tried unsuccessfully to put pressure on him to behave better in front of the others.

A concern for the opinions of others may sometimes cause a parent to over-react to a child's actual or imagined misbehavior, particularly if those others have equal claims on the household territory. This story was told by the veteran of several communal situations about her first experience:

Dan (nine years old) was the oldest child. He
moved in with a new child who was just
crawling and getting into things. He had had a
separate room, and then he had to share. Gary
was $11 / 2$ years younger than Dan. They were
different kinds of kids-Gary was more
energetic, Dan more long-term and concen-
trated. Everyone had expectations of Dan as
the older kid: to be the intermediary between
adults and kids, to take care of the younger
ones, to be super. He began to make hideouts
to hide in, to get away from the pressure. One
day Dan and Gary were playing wildly in the
living room, and Gary fell and hurt his head.
Dan said he had fallen. Leslie, Gary's mother,
said Dan had pushed him, I believed her. I
didn't see where Dan was coming from, as he
maintained for months that he hadn't pushed
Gary. I went crazy at the time. One night
Leslie and Fred (Gary's father) and another
person in the house persuaded me to take Dan
to a child therapist and to go to one myself-I
was so invested in other people's opinions. . .
I later understood that Leslie's fears of Gary
getting hurt were a projection of her own
violence. I also found out long after, from
another adult, that Dan was telling the truth.

Parental identification with children's images in the presence of others, then, 
sometimes means that parents experience their limited control more acutely. The audience makes them aware by reflection of what control they can and cannot exercise over their children.

If the presence of an audience, then, heightens issues of "reflected identity"the concern that one family member will be "judged" by the behavior of another, it also makes possible new alliances that affect parent-child relations. The others represent potential coalition partners for both parent and child and make possible a number of relationship configurations. First, the others may attempt to gain influence over either the parent or the child-in the first case by indicating that the parent should exert more control over the child, in the second, less. To the extent that a parent desires a positive relationship with a third party, then, he or she may be relatively easily induced to occasionally turn against his or her child, to "side with" the other against the child, in order to make the child's behavior acceptable to the other so that the parent herself will be acceptable.

\section{Separate Relationships and Multiple Rule-Makers}

Parents also experience loss of control over the child's experiences, environment, and relationships. Parents were no longer the principal rule-makers and rule-enforcers for their children. Other adults had the right to make and enforce rules for the joint household, to make demands on the children, to provide experiences for them, and form relationships with them. In a few instances, though rare, other members of the household encouraged the child to do something that contradicted parental rules or behaved toward the child in ways that violated the spirit of the parents' desires. Parents could avoid this only to the extent that they could control the other adults in the household-an unlikely occurrence among a group of adults valuing egalitarian participation. Thus, for parents to remain in force as principal rule-makers and rule-enforcers for their children, they must also have power in the commune, be able to enforce rules for the other adults.
What in the private family is a relative simple (structurally) matter of negotiation between two parents or a strong stand by one in order to define norms affecting a child becomes in the commune an even more complicated political situation.

In a political context, the demands or requests of parents concerning their children may, indeed, sometimes be seen as power moves on their part, as a way to gain special privilege or undue influence in the group and may in extreme cases be responded to in political ways regardless of the real needs of the child. More than one parent in houses with relatively few kids reported his or her difficulty convincing others in the house that the children were not just miniature adults but had special needs and required special kinds of behavior. For example:

\begin{abstract}
We have been easier on the kids than the other adults in the house would believe we should be, in terms of sharing responsibility. . . It's been a disagreement between us and the other adults about whether a six- or seven-year-old child is capable of doing an adult's share or any very substantial share of a large household's chores.
\end{abstract}

Some of this difficulty could have resulted from the ignorance of nonparents and/or their unwillingness to engage in special efforts; but part of it may also be attributable to a reluctance to acknowledge the special status of child and, by implication, parent. In houses with relatively more children and parents-so that the threat of special status was reduced-parents did not report the same phenomenon.

Parents generally had strong feelings about the ways others related to their children; their reactions to the relationships sometimes included frustration at their lack of control. Complaints about others' behavior toward a child were frequent; overt expressions of jealousy about anothers' positive or strong relationship with a child were rare and far from automatically being the child's emissary and intermediary to others outside the family, in some cases, parents may not even be the first to know what issues occur 
around their children, and they may be limited in their ability to effect change.

One outcome is that children gain more autonomy and a measure of individuation similar to that occurring for couples when third parties are available to form relationships outside of the intimate dyad. Children quickly learn what resources and relationships exist for them in the house and, often, how to manage them themselves. Sometimes other adults besides the parent may intervene on the child's behalf, and it is not at all clear that final authority or final knowledge always rests with the parent. Children themselves choose which adult to confide in or ask for advice. In one group, an 11-year-old formed a strong friendship with a woman in her twenties, who replaced the mother as principal "expert" on what was happening with Monica and what would be best for her. Under such circumstances parents occasionally felt that other people could influence their children more readily than they could. According to one report:

\footnotetext{
Keith was in the five-year-old demand stage. Two other women decided they didn't want to be ordered around. They taught him to say please and thank you. They accomplished this-a nonparent can do this more easily - in the space of about ten days.
}

Competition and conflict over what kinds of child rearing standards would prevail was frequent. In one household, two mothers with young daughters fought about child rearing strategies; one felt the other too permissive, the other thought the first too strict. The feeling that permissiveness or authority in the other is bad for a child is hard to deal with for people with a rhetoric of freedom. Since the two mothers shared child care, they also had to cope with the results of the other's style. One of them finally moved out, saying that while she intended to continue living communally, she wanted to be the only parent next time, pointing up the politics of the situation. Another household broke up over the issue. Two couples had infants and were uncomfortable with the personal style of the other set of parents and what impact that style would have on their ability to influence their child as they wished. In a third case, the conflict between parental styles resulted in different sets of rules being enforced for the children of each set of parents, causing the groups' major issue of the first year. One parent unit was very strict and controlling, making demands on the children to work; the other felt that kids could decide all things. Their children shared a room, and over time the conflict built up. One child would have to go to sleep while the other sat outside and watched TV. This situation was resolved by the children forming a coalition to defeat both sets of parents.

\section{Parental Domains}

We have already indicated that some parents retain, willingly or unwillingly, a number of child care responsibilities, but over all of the groups studied, it becomes clear that it is not particular duties and chores that distinguish parents from nonparents in communal households. Depending on the household, nonparents are likely to be found at any time with children, and children are likely to form close relationships with at least one person other than a parent. What does distinguish the domain remaining more exclusively in parental hands is the parents' legitimate involvement with the general boundaries of relationships and experiences for the child. Parents tend to reserve for themselves the rights to protect their children and to punish them.

The kinds of protection reported included speaking up for children when they were unfairly treated (one mother called it "running defense for my child"), trying to get them the extra things they needed from the house or others, or defending children against the criticism of others. Parents often preserved a spacê and time of the day that was known to be exclusively for the parents and children to be together, alone and safe from interruption-often in the children's room just before bedtime, when other house members would have retreated to private activities and the house was quiet, or in the parents' room if the children's room was 
shared with nonsiblings. The specialness of these times of safety and closeness is manifest in interviews with communal children.

Only in cases where the parent had explicitly conferred the privilege of invoking sanctions against children upon certain adults was such an adult activity permitted. The bestowal of this privilege occurred rarely. In only one household did the mother specifically allow certain male communal members to invoke sanctions with her children. These male members exercised this privilege in telling children in cases of rule violations to go to their rooms and to leave the table at dinnertime. But it was clear that they were acting for the mother.

Parenting in the presence of others, then, is complex and, like coupling, involves its own delicate balances: help with child care versus retention of the exclusiveness of parenting; concern for the child versus concern for the reactions of others; children's separate relationships with others versus parents' desires to protect their children; letting go of burdens versus losing control. Parents both applaud their children's exposure to a variety of relationships and styles and mourn the loss of parental sovereignty. A single father said:

\begin{abstract}
In comparison to a nuclear family, the fact that communes bring a child in contact with a variety of people of different styles, ages, tastes, makes communal upbringing better. But there are times when communes seem to leave out extreme love and tight relationships; I feel these are important in a person's life. The multiplicity of relationships of the nuclear family. Fay (his daughter) and I have gained a great deal, and also we've lost a little too.
\end{abstract}

\section{Children: Multiple Relationships and Multiple Rule-Makers}

The presence of others appears to offer a number of freedoms and skills for children while adding other constraints. (We include in the category of "children" ages four-twelve.) Children have a variety of adult relationship partners, and, in forming multiple relationships, learn to make choices and learn to express themselves easily to grown-ups. Children themselves become the audience for a number of adult-adult exchanges over the dinner table or at house meetings, including conflict between their own parents and the others. Parents and other adults become demystified by this process; their own weaknesses and norm violations are exposed. Urban communal households shield children from sex and drugs (though drug use itself is infrequent) and occasionally from heavy or late house meetings-but not from discussion about these matters or other affairs or adult life. Aware of house conflicts, children also become aware of times when their own parents are in the wrong or have mispleased others or have failed to get their way on issues; the "front" of parental strength is more difficult to maintain. Older children may even form coalitions on the side of others rather than their parents. In addition, the presence of others and therefore the enlarged size and complexity of the households mean that children have to learn to "speak up" in order to be heard, to be persuasive and interpersonally skilled in order to get something they want. In a comment that echoed other parents, one mother said of her five year old who had lived communally for a year:

\footnotetext{
He's more sophisticated, less of a baby. He's more aware of dynamics between people. It's easier for him to talk to people and to express himself in words-between parents and children, there's a lot of nonverbal stuff. With the others, he's learned a lot about expressing himself, and he's exposed to so much.
}

The possibility for multiple relationships and observation of adults in communal households also brings the possibility for constraints-particularly when children are scarce and the household is numerically as well as socially adult-dominated. As parents lose exclusive control, other adults gain the right to impose control over their relationships with children and the household. More people in the house may also mean more people telling the child what to do, observing deviance, and imposing con- 
straints as well as providing knowledge, company, and support.

\section{The "Cinderella Effect": Children and Rule-Making}

Children of four-twelve almost universally experienced communal living as a situation involving "too many bosses" or "too many people saying 'stop that' "especially in houses with few other children and crowded quarters. We can call this the "Cinderella effect" ("Cinderella do this; Cinderella, do that") to capture the experience of multiple rulemakers and rule-enforcers. As one child explained:

\footnotetext{
Sometimes it's not so fun to live here because there's a lot of people that chase you around and tell you what to do. . . Like they tell me sometimes when I'm sneaking food, they say 'stop eating all the food, it's almost dinnertime.' And sometimes they say, 'don't stand on the chairs, that chair is very weak,' or 'don't run around the dining room table when we're eating because it shakes and spills all the coffee and the milk and the water.'
}

Soon after entry, new communal residents generally formulate rules governing his or her private space. These rules often pertain to adults; but, given the presence of children in the commune, they invariably govern specific usage of the space by the child. These rules specify whether the individual's room may be used by children, under what conditions (if any) it may be used by children (to watch TV, to play in), at what times of the day it may be used by children, if the owner must be present or must be absent during the usage period, whether prior permission must be requested, to whom one must request permission (to the owner or in the case of absence, to a parent), and how one requests such permission (by knocking or orally). Generally such rules clarify the meaning of such territorial boundary markers as the closed door-whether this signal means the room is completely off limits, or whether it means that the child may knock to request permission to enter.

In addition to rules about private space, each communal member may formulate rules governing use of private property- e.g., possessions both in the private space and in the communal spaces. Following an individual's move into a communal household, he or she often 'donates' property temporarily (usually in the form of furniture, kitchenware, TV's, or stereos) to the group. However, usage, maintenance, and control of the property, is still a prerogative reserved by the individual owner and is frequently exercised whenever such property is being misused. As children have often not yet learned the taken-for-granted adult usage patterns of property, rules for children's property use are frequently formulated.

Because of their limited mobility, resources, and short 'work' day, children often spend considerable time at home and are frequent users of communal space. This frequency and the quantity of paraphenalia involved (toys, games, paper, crayons, and so forth) means that kids are frequently violators of rules of neatness and spatial order. Or, as one parent explained:

One of the problems here with Sherri that is
abrasive is the mess she makes and how re-
sponsible she is for cleaning up after herself
. . being forgetful and people not liking that,
particularly so in the TV room which is a com-
monly used room by a lot of people. There's
sort of a trail of Sherri throughout the house.
We've tried keeping boxes in certain places
where she could keep all her stuff, but other
people, aside from me and Dick (her father)
get after her if it's annoying to them.

In meetings, rules are formulated setting forth explicit expectations for children in terms of their maintenance of the communal space. In some houses it was after the pressure of several communal members that the rotation of household tasks came to specify the degree of participation required of kids. As the mother of several children explained:

The kids' lack of responsibility got to some of the people, especially to two particular adults who were annoyed that the kids did not do much around the house. Since all the people here had shared responsibilities the adults felt that the children too should have shared responsibility, cleaning the house and picking up after themselves. Previously the kids had had no stated responsbilities-they were occasion- 
ally asked from time to time to do certain chores, but they were not included in the rotation of household responsibilities. So we had a group meeting and decided that the children should be included at the next meeting since we were talking about responsibilitites in the house for them.

Divisions of labor involving children in household maintenance tasks were commonly found in urban communes. And, children frequently voiced their awareness of the expectation of adult communal members that they 'do their chore' for the week.

Group meetings are also settings for rule-making about children's usage of communal space. The primary spatial violation by children concerns noise. Often rules specify the types of noise permitted and in which areas, the hours when noise is prohibited (early morning, late at night), the types of noise-generating activities (parties, fighting) prohibited.

Rules may also define when the child must stop using communal space; bedtime is a time when children must vacate the communal areas. Although bedtime decisions are most often formulated by parents, occasionally others make such decisions at group meetings. One parent of several children reported:

\footnotetext{
Children here were very much brought up by the group in that decisions even relative to bedtime were reached by the community. Bedtime has been a big bone of contention with the children. . . they have a very natural curiosity to be part of whatever is going on in the evening, at which point myself and the rest of the people had just had enough of kids. Most people here were not working 9 to 5 and instead worked in the house. . they would be here in the afternoon when the children got home from school, and so by evening, they had had enough of kids.
}

In group meetings, rules are conveyed and made more explicit to children, and the role of nonparent others in controlling children's experiences is supported. If, for example, an adult has told a child not to enter a room without knocking, at a group meeting the adult may reinforce the rule publicly to the child. Often too, group meetings are settings where rules are evaluated-those which have been formu- lated and made explicit may be judged to have failed, and new rules are then formulated to better deal with the issue. As a nine-year-old boy explains what happened to him:

I'm not allowed to walk in people's room if their door's closed. . . But, if you do one mistake and then you do it again, maybe you do a a mistake when you didn't know that rule and you say, 'I didn't know it.' And so they say, well, now you know it.' And then if you break it then, then they bring it up in the next meeting and then they talk about it and then they get an even bigger rule, like you can't even go into this room if the door's open.

\section{Rule-Enforcing}

The presence of many adults in the home territory ensures a large number of adults engaged not only in rule-making but also in rule-enforcing. Methods of rule-enforcing may include constant repetitions of the rule to the child, and the use of threats or sanctions. Repetition of a rule was the most common means of enforcement: "don't stand on chairs," "don't eat all the food before dinner," “don't interrupt," "pick up your things in the TV room and put them in your room." Threats frequently contained a contingentresponsibility clause: "If you break that, you'll have to pay for it (or fix it)" or "if you mess up my room when you come in here, then you'll have to clean it up." The threat generally functioned sufficiently as a deterrent so that threats tended to be rarely enforced. More severe sanctions, as we mentioned earlier, were reserved to parents.

The existence of the "Cinderella effect," having multiple rule-makers and ruleenforcers, may create various problematical situations for children, including inconsistency, ambiguity, and contradictions. Difficulties arise because each adult communal member has a different set of expectations concerning what is appropriate child behavior and each adult has different definitions of what constitutes an infraction. The noise issue highlights the different adults' sets of expectations and definitions of what constitutes "too much noise" on the part of the children. What is 
an appropriate or acceptable noise level for children to many adults is often considered excessive noise by others. One mother said:

\begin{abstract}
There are adults here who react differently than I would. I can see encounters that are handled differently than I would handle them. Sometimes people are stricter or often less patient with noise. For instance, when the girls are making noise, someone might say 'you're making noise, you'll have to go do that somewhere else,' at a time when I probably wouldn't have even bothered to say that.
\end{abstract}

Different expectations and definitions may result in inconsistent rule-enforcement. Thus, what a parent might consider an activity or action that falls within an acceptable range of child behavior, another communal adult may not. The child is faced with an inconsistency: the definition of the rule varies from adult to adult and similarly, the definition of their adherence to the rule varies from adult to adult. Rule-enforcement thus becomes a highly arbitrary process for chilren-fixed at the whim of many different adults. Children often adjust to this and learn that adult standards differ and, depending on their ages, may also use these differences to make choices about which set of standards to ignore. But because adults have more power, children are likely to be called on all of their norm violations. In fact more authoritative behavior seems to come out around kids than any other area of communal life-the release of authoritarian tendencies in a democratic social structure.

Rule-enforcement may also be contradictory. What some adults have explicitly allowed, others may have prohibited. Thus, a child may be permitted to watch television in one adult's room while the same act may be explicitly prohibited by another adult in the latter's room. Similar contradictory rule-enforcement arose for a 4-1/2-year-old-boy when his father was out one evening. His bedtime had been established by his father as 8 p.m. Another member, a woman whom the father had asked to put the boy to bed, enforced a 7 p.m. bedtime rule despite the boy's protestations to the contrary. In such situations the child is very often caught between "Scylla" and "Charybdis"-maneuvering the waters between the "great powers" can be a frustrating task.

Another consequence of the presence of others as rule-makers and rule-enforcers is the likelihood that children will experience the conditions of 'double jeopardy'having an infraction noticed more than once and being reprimanded more than once for the same offense. The large number of adults living in the communal home territory increases the likelihood that many will be present in the home territory at the same time. This simultaneously increases the likelihood that more than one adult will notice a child's rule-breaking offense during a short time period. Often then, more than one adult reprimands a child for the same offensescolding a child or asking him to follow a rule without realizing that another adult, just a few moments before, may have cited him for the same offense.

A variation on the theme of 'double jeopardy' arises when the child may be reprimanded by one adult to follow one rule (such as picking up his toys in the living room) moments after another adult has reprimanded him to follow a different rule (to clean up his mess in the kitchen). This epitomizes the consequences of the "Cinderella effect" - "Cinderella, do this!" "Cinderella, do that!" "No, Cinderella, do this!" A child's response to this situation is described by a six-yearold's mother:

\begin{abstract}
What really drives Ethan crazy is if someone says to him 'Ethan, do this,' and somebody else has just said to him previously, 'Ethan, do this,' and he's in the process of doing that thing when somebody says, 'do this.' That really flips him out. That must be one of the most difficult experiences for him here.
\end{abstract}

Recourse to a higher court of appeal (e.g., parent) is rare for communal children; parents themselves make the decision to protect their children only in extreme circumstances and do not intercede for children unless greatly provoked. When another adult makes a rule or reprimands a child as rule-enforcement, 
that adult's word is law-and generally not subject to amendment or reversal. One of the desires most frequently expressed by parents in communes with children and adults is that each communal adult member have a distinct relationship with the children. Parents encourage other adults to have 'their own' relationships to each child. This functions especially in terms of gripes - that parents prefer adults to deal directly with the child rather than express it to them as middlemen. As one mother explained: "The norm here is if that child is bothering you, it's your problem, not mine. I don't want to hear about it. Deal with the child." Depending on their age, children may come to house meetings and complain of unfair treatment, just as any member can bring up a grievance; occasionally children have influenced a change of rules.

It must be recognized, of course, that the participation of each adult in rule-making and rule-enforcement for children depends on a number of variables, including length of time as communal resident, time spent daily in the home territory, familiarity with children in general and with those specific children, familiarity with child's parents, and view of children (as a special category or as little adults). The extensiveness of communal constraints on children and whether children face arbitrary adult domination varies also with the number of children and the degree of crowding in the household. More children and more space reduce the continual control fewer children in more cramped quarters face, partly because children gain their own territory and become a more critical mass for the household, so that their own status as children can be more easily acknowledged and incorporated into household routine. With more children, kids can form their own coalitions.

It should also be noted that there can be areas of freedom as well as constraint for kids in communal houses: differentiation from parents, demystification of parents, multiple relationships with those adults available to children, and the ability to effectively use the disagreements between adults to gain freedom. Further, the wider visibility of adult behavior in such households and the generally more experimental behavior and permissive norms means that communal children often have behavioral freedoms their neighbors lack despite rules about use of space and property; one mother reported that her kids' friends find the commune a very free place "where they are allowed to swear."

But in general the presence of a large number of adults in the children's home territory, then, increases the likelihood of a large number of adults participating in rule-making and rule-enforcing vis-a-vis these children-what has been here termed the "Cinderella pheonomenon." This phenomenon consists of arbitrary, inconsistent, and contradictory rule-enforcement where situations of 'double jeopardy' (reprimands for the same offense) are likely to occur and where the child has no recourse to a higher court of appeal. Under such circumstances parents are not the dominant sources of social control for their children in the household.

\section{Conclusion}

We have explored some of the impacts of the presence of others on the most intimate human relationships: those of couples and parents and children in communal households. The shift from essentially dyadic to larger group relations in the home adds a number of complex phenomena: audiences, alternative resources, coalition partners, interventions, and political jockeying. In each kind of relationship the primary tie may remain central for many people while they balance availability and responsibility to the others. The major effects in both cases involve a shift in the locus of social control. There are both greater opportunities for wider intimacy, more ties, sharing of chores and responsibilities, autonomy, and egalitarianism and a series of new issues with which couples, parents, and children must cope.

Some of these issues arise as a function 
of an ideology and culture particular to American communal households in the 1970's, but others are structural effects of the "presence of others." We would expect similar structural effects in other circumstances in which intimate relations are conducted on more public territory, whether extended family households, utopian communities, multiple family therapy, close-knit urban neighborhoods with minimal private space, or families with boarders or lodgers.

\section{REFERENCES}

Caplow, Theodore. Two Against One: Coalitions in Triads. Englewood Cliffs: Prentice-Hall, 1968.

Coser, Lewis A. Greedy Organizations. New York: Free Press, 1974.

Jaffe, Dennis T. Couples in Communes. Unpublished doctoral dissertation, Yale University, 1975.
Jaffe, Dennis T. and Rosabeth Moss Kanter. Couple Strain in Communal Households: A Four-Factor Model of the Separation Process. Journal of Social Issues, in press.

Kanter, Rosabeth Moss. Commitment and Community: Communes and Utopias in Sociological Perspective. Cambridge: Harvard University Press, 1972a.

Kanter, Rosabeth Moss. Communes in Cities. Working Papers for a New Society, 1974, 2, 36-45.

Kanter, Rosabeth Moss. The Family and Sex Roles in American Communes. In Rosabeth Moss Kanter (Ed.), Communes: Creating and Managing the Collective Life. New York: Harper and Row, 1973.

Kanter, Rosabeth Moss. Getting It All Together: Some Group Issues in Communes. American Journal of Orthopsychiatry, 1972b, 42, 632-43.

Kanter, Rosabeth Moss and Marilyn Halter. Dehousewifing Women, Domesticating Men: Equality between the Sexes in Urban Communes. Presented at the 1973 Meetings of the American Psychological Association.

Slater, Philip E. On Social Regression. American Sociological Review, 1963, 28, 339-64.

Simmel, Georg. The Sociology of Georg Simmel. Kurt Wolff (Ed.). Glencoe, IL: Free Press, 1950.

Weisberg, D. Kelly. Children and Communal Life. Unpublished doctoral dissertation, Brandeis University, 1975. 